\title{
Chronic back pain cured by low-dose levodopa: is it a variant of restless legs syndrome?
}

This article was published in the following Dove Press journal: Journal of Pain Research

\section{Zhi-Fen Zeng \\ Yan-Ran Liang \\ Ying Chen \\ Xiu-Na Jing \\ Su-Dan Peng \\ En-Xiang Tao}

Department of Neurology, Sun Yatsen Memorial Hospital, Sun Yat-sen University, Guangzhou, Guangdong, China
Correspondence: En-Xiang Tao Department of Neurology, Sun Yatsen Memorial Hospital, Sun Yat-sen University, No.I07 Yanjiang West Road, Guangzhou, Guangdong 518000, China

Tel +862081332263

Fax +862081332802

Email taoenxiang9@163.com

\begin{abstract}
Chronic back pain is one of the most common reasons for missed work and visits to the doctor. This report presents 2 interesting cases of chronic back pain that were effectively relieved by low-dose levodopa. These 2 patients showed no sign of anatomical problem of the spine or relative structures, but the discomforts on the back manifested some characteristics resembling those in restless legs syndrome (RLS), and one of them actually developed RLS after many years of back problem. We believe that this type of chronic back pain might be a variant of RLS, which we would like to call "restless back", and it can be effectively treated by dopaminergic drugs.
\end{abstract}

Keywords: chronic back pain, restless legs syndrome, levodopa

\section{Introduction}

Chronic back pain is not only one of the most common reasons for missed work and visits to the doctor but also a leading cause of disability. ${ }^{1}$ The cause of chronic back pain can be very complicated, and numerous cases are classified as non-specific, that is, of unknown origin. Despite the growing use of nonsteroidal anti-inflammatory drugs, muscle relaxants, opioid analgesics, physical therapies, and psychological support, the pain in some patients of this category is still not relieved. Interestingly, we have observed 2 cases of chronic back pain that were relieved dramatically by lowdose levodopa in our clinic. As far as we review, this situation is rare and we think it deserves more concerns and further research.

\section{Case description Case I}

A 47-year-old previously healthy woman complained of pain and indefinable discomfort over the back for 7 years. The symptoms started from her hips and lower back then spread to the whole back in 2-3 years, involving her shoulders. She suffered from soreness and swelling of the muscles, and sometimes "itchiness in the bones" as described by the patient. The symptoms became worse when she was holding a fixed posture or trying to sleep at night. She always felt an urge to move like by twisting, bending, stretching the back, or punching it with her own fists, and such movements relieved her discomfort temporarily. Her visual analog scale (VAS) score for pain was $6 / 10$ at the first visit to our clinic. She had a history of 2 pregnancies and 5 years of insomnia. She denied any history of anemia or iron deficiency. Her medication included 
a discontinuous use of benzodiazepine. She did not smoke or use excessive caffeine or alcohol. There was no family history of movement disorders or sleep disorders. An MRI scan of the spine and brain did not yield any remarkable findings, neither did laboratory tests, including blood cell count, serum chemistry, thyroid tests, rheumatoid markers, human leukocyte antigen B27, serum iron $(7.2 \mu \mathrm{mol} / \mathrm{L}$, references 7.0-32.0) and serum ferritin level $(87 \mathrm{ng} / \mathrm{mL}$, references 28-365), vitamin12, and folic acid level. She was diagnosed as having general anxiety, and amitriptyline was prescribed. Her sleep problem mildly improved but her back discomfort remained the same. After 3 months of amitriptyline $(25 \mathrm{mg} /$ day; Changzhou Siyao Pharm, Changzhou, China), paroxetine (20 mg/day; Glaxo Smith Kline, Brentford, UK) was added for another half year, still, her back symptoms were not alleviated. We reconsidered our diagnosis, and the diagnosis of "Restless Back" was suspected. The patient fulfilled the 4 criteria of restless legs syndrome (RLS) according to the updated International RLS Study Group (IRLSSG) consensus criteria except that her symptoms happened in the back rather than legs: 1) an urge to move accompanied by unpleasant sensations over the back, 2) the urge to move and the accompanying unpleasant sensations worsened during periods of rest or inactivity such as lying down or sitting, 3 ) the aforementioned symptoms were relieved partially or totally by movement, such as walking or stretching, 4) the symptoms became worse in the evening or night than during the day. ${ }^{2}$ The aforementioned features could not be explained by anxiety, positional discomfort, or myalgia. The rheumatoid tests and MRI scan excluded the condition of rheumatoid arthritis or ankylosing spondylitis. The response to dopaminergic treatment is very informative as the RLS is concerned. So, we started treatment 10 months ago by adding levodopa with benserazide at a ratio of 4:1 (125 mg of Madopar ${ }^{\circledR}$, twice a day; Roche, Basel, Switzerland). Her back pain and discomfort, together with discomfort over hips and shoulders were significantly relieved, with a VAS score of 2/10 in a 2-week follow-up visit. After that, we gradually tailed down paroxetine, which was finally off in 3 months. Currently, the patient is only taking levodopa + benserazide (125 mg of Madopar, twice a day) and amitriptyline (12.5 $\mathrm{mg} /$ day) that control her symptoms well.

\section{Case 2}

A 52-year-old female gynecologist complained of lower back pain for almost 15 years. The pain was more disturbing when she was performing an operation, but neither resting at night gave her any relief nor did analgesics like celecoxib and acet- aminophen. "The pain is not serious but it's really disturbing and distracting. Sometimes it keeps you awake all night, just twisting from side to side", according to the patient. However, exercises and massages could ease her discomfort temporarily. According to her previous medical record, her VAS score for pain varied from $3 / 10$ to $5 / 10$. Her MRI scan showed no abnormalities in her brain and a minor prolapse over L3/L4, L4/L5 intervertebral discs, while laboratory tests indicated only a slight increase in low-density lipoprotein level. Her serum iron level was $10.6 \mu \mathrm{mol} / \mathrm{L}$ (references 7.0-32.0), and the serum ferritin level was $36 \mathrm{ng} / \mathrm{mL}$ (references 28-365). She had a history of high blood pressure and had been taking amlodipine for 3 years. She also had a history of 2 pregnancies. A careful investigation into her family history revealed a highly probable case of RLS in her uncle (her father's brother). She did not get satisfying treatment until she started to have unwanted feelings over her legs 1 year ago, which brought her to our clinic. RLS was diagnosed with a RLS rating scale (RLSRS) of 18 points (by the updated IRLSSG criteria $)^{2}$ and levodopa with benserazide (125 mg of Madopar, twice a day; Roche) was prescribed. She surprisingly noted that her backache was effectively relieved at the same time as her restless legs symptoms being controlled. She reported being pain free (VAS 0/10) and got a score of 3 points in an RLSRS in the latest evaluation (2 months ago).

\section{Discussion}

The aforementioned are 2 seemingly common cases of nonspecific chronic back pain in middle-aged women, but if we analyze them in detail, we can see that they had their own features. First, the back pains in both cases were not prominent, but accompanied by some other indefinable feelings such as soreness, swelling, itchiness, etc. Second, the back pain was more intolerable when the patients were at rest or in a fixed posture, and it was relieved by back movements and exercises. Third, both patients had sleep problem and excessive movements at night. Therefore, we could not help associating these cases with RLS and suspected that they had some similar pathophysiologic mechanisms. The positive treatment response to levodopa gave us more evidence to believe that this type of chronic back pain is a variant of RLS, or a certain episode of it.

RLS is a common neurological disorder characterized by disagreeable sensation in the legs, which is relieved by movement. Mild or intermittent RLS is usually treated with low-dose levodopa, and the first-line treatment for moderateto-severe RLS is dopaminergic agonists. However, the restless feeling is not limited to the legs. It is reported that up to 
$48.7 \%$ of patients with RLS might experience restlessness in their upper limbs in the later course of the disease, and some even have expansion to the face.,4 "Restless Arms Syndrome" refers to those sporadic cases in which restlessness occurs initially or solely in the upper extremities. ${ }^{5,6}$ In even rarer situation, restlessness starts from one's chest or back. ${ }^{7,8}$ The tricky thing is that, when restlessness happens in the back, it can be described as all kinds of feelings such as pain, soreness, fatigue, swelling, itching, etc. In the 2 cases we presented previously, the "restless back" appeared in the form of chronic back pain, and therefore was not treated appropriately for a long time.

Although the exact pathogenesis of RLS is still not known, brain iron deficiency and abnormalities of dopamine system have been suggested as possible causes. However, none of the current theories can explain why RLS symptoms mostly happen in the lower limbs. Some reports used MRI to show decreased brain iron in certain areas like the substantia nigra, to a lesser extent, the putamen and caudate, or even in the thalamus. ${ }^{9-12}$ But those studies were done on typical RLS subjects, not including those with symptoms in the arms or trunk. If we have enough cases, it will be meaningful to see whether there are any differences in the brain iron distribution between different types of RLS.

We report these cases to propose a new concept of a "restless back," referring to the restlessness that occurs initially or solely in the back. Even though the exact pathogenesis is not known, physicians should be aware of this possible variant of RLS, and that treatment by dopaminergic drugs has been proven to be very effective.

\section{Conclusion}

The "restless back," which might be a rare variant of RLS, may exist in patients who complain of chronic back pain. Careful differentiation and correct diagnosis would be of great importance in view of the significant response to dopaminergic treatment.

Journal of Pain Research

\section{Publish your work in this journal}

The Journal of Pain Research is an international, peer reviewed, open access, online journal that welcomes laboratory and clinical findings in the fields of pain research and the prevention and management of pain. Original research, reviews, symposium reports, hypothesis formation and commentaries are all considered for publication

\section{Acknowledgment}

This work was supported by the National Natural Science Foundation of China (81771378). Written informed consent has been obtained from the patients to have the case details published.

\section{Disclosure}

The authors report no conflicts of interest in this work.

\section{References}

1. Vos T, Flaxman AD, Naghavi M, et al. Years lived with disability (YLDs) for 1160 sequelae of 289 diseases and injuries 1990-2010: a systematic analysis for the Global Burden of Disease Study 2010. Lancet. 2012;380(9859):2163-2196.

2. Allen RP, Picchietti DL, Garcia-Borreguero D, et al; International Restless Legs Syndrome Study Group. Restless legs syndrome/WillisEkbom disease diagnostic criteria: updated International Restless Legs Syndrome Study Group (IRLSSG) consensus criteria-history, rationale, description, and significance. Sleep Med. 2014;15(8):860-873.

3. Michaud M, Chabli A, Lavigne G, Montplaisir J. Arm restlessness in patients with restless legs syndrome. Mov Disord. 2000;15(2):289-293.

4. Buchfuhrer MJ. Restless legs syndrome (RLS) with expansion of symptoms to the face. Sleep Med. 2008;9(2):188-190.

5. Ruppert E, Cretin B, Meyer C, Kilic-Huck U, Bourgin P. Characterization of periodic upper limb movement disorder in a patient with restless arms syndrome. Mov Disord. 2012;27(11):1459-1461.

6. Ruppert E, Tranchant C, Kilic-Huck U, Carpentier N, Bataillard M, Bourgin P. Bedtime-related jerks in the upper limbs associated with restless arms syndrome. Neurology. 2015;84(9):959.

7. Umehara H, Sumitani S, Ohmori T. Restless legs syndrome with chest and back restlessness as the initial symptom. Psychiatry Clin Neurosci. 2010;64(2):211.

8. Suzuki K, Miyamoto M, Miyamoto T, et al. Restless "lower back" in a patient with Parkinson's Disease. Tremor Other Hyperkinet Mov. 2013;3: tre-03-195-4313-2.

9. Alen RP, Barker PB, Wehrl FW, Song HK, Earley CJ. MRI measurement of brain iron in patients with restless legs syndrome. Neurology. 2001;56(2):263-265.

10. Earley CJ, Barker BP, Horska A, Allen RP. MRI-determined regional brain iron concentrations in early and late-onset restless legs syndrome. Sleep Med. 2006;7(5):458-461.

11. Godau J, Klose U, Di Santo A, Schweitzer K, Berg D. Multiregional brain iron deficiency in restless legs syndrome. Mov Disord. 2008;23(8):1184-1187.

12. Moon HJ, Chang Y, Lee YS, et al. T2 relaxometry using 3.0-tesla magnetic resonance imaging of the brain in early- and late-onset restless legs syndrome. J Clin Neurol. 2014;10(3):197-202.
The manuscript management system is completely online and includes a very quick and fair peer-review system, which is all easy to use. Visit http://www.dovepress.com/testimonials.php to read real quotes from published authors. 